\title{
An Experiential Learning Approach to Fostering Learner Autonomy among Omani Students
}

\author{
Anita Teresa Boggu \\ Faculty of English Language Studies, Majan University College, Oman \\ J. Sundarsingh \\ Department of English, Karunya Institute of Technology and Sciences, Coimbatore, India
}

\begin{abstract}
Experiential learning is a learner-facilitating tool that has not been sufficiently explored in Higher education institutions in Oman. There is a growing body of literature that recognises the importance of 'learning by doing,' 'hands-on approach' or 'experiential learning.' Experiential learning grew in popularity with adult learners since the time of Dewey and progressed with several scholars researching on the potential benefits of applying experiential learning methods in vocational and technical training institutions. The notion that knowledge is gained through active involvement in a specific task is a construct that has been researched in the present study. It endeavours to foster learner autonomy through the implementation of instructional tasks based on Kolb's experiential learning cycle. The main objective was to observe the change in perceptions of learners on their autonomous behaviour before and after the intervention. Through convenience sampling of 60 undergraduate students, enrolled for various pathways on the business programme were selected for this study. The quantitative data was collected by administering a learner autonomy questionnaire and a set of selfdesigned experiential learning classroom activities. The findings of the study revealed that experiential learning cycle activities implicitly fostered learner autonomy and enabled learning necessary skills for the workplace.
\end{abstract}

Index Terms-learning cycle, learner autonomy, responsibilities, experiences, reflection, the experiential learning method

\section{INTRODUCTION}

Numerous seminars, workshops, and educational meets are regularly organised to deliberate on educational practices that would bridge the gap between theoretical knowledge and employability skills. Research has shown that employers in Oman are dissatisfied with the graduates that exit higher education institutions. Several Omani researchers have observed that the problem arises from schools and this is carried forward to the tertiary institutions. As quoted by (Albulushi, 2012), grade 12 graduates who enter tertiary institutions lack the ability to, "use language effectively and appropriately in all four skills throughout the range of social, personal, school, and work situations required for daily living in a given society". This is not only the case with schools but also with a large number of students who were awarded scholarships to study abroad in English speaking countries (pg 142,143).

The Oman government has strenuously put in efforts to elevate English language teaching to cater to the demands of the global market. The drive towards higher education development was manifested at a conference held in Muscat in March 2001. The theme of the conference was,' The University of the 21st Century' (Al-Hussaini, 2001) gives an account of the recurring themes of the conference, "Globalisation, skills in information technology, the shift from teaching to learning, a lifelong learning culture and the need to involve private sector in higher education". He notes that the conference and the themes were conducted at the right time as he states that "higher education - especially professional education - lies fettered by examination-oriented courses that are rigid, pattern-bound and overcrowded. Many students fail to acquire professional skills, self-learning ability and the right ethical attitudes' (pg 1).

(AL-DHAFIRY, 2003) expresses disappointment at the state of the educational systems in the GCC countries and highlights the gap between graduates and the needs of the labour market. As a result of weak basic skills, there is a surge in unemployment (pg 65). Furthermore, he brings to our attention that soft skills are gaining importance in the labour market. Cited in (Al-bulushi, 2012), Akkari 2004, calls for a need to develop technical skills, such as problemsolving, innovation, critical thinking, cooperation and creativity ( pg 146-147). As observed from the studies discussed, there is a dire need of a major transformation in the educational system. The country's economic development is closely linked to adequate human capital, 'the graduates.' To corroborate the requirement, the eleventh philosophy of education document is listed. The Sultanate of Oman laid down a set of 16 principles of 'Philosophy of Education.' Specific objectives are derived from these 16 philosophies. Philosophy of education number 11, is enumerated here as it relates to the main aim of the current study. (Philosophy of Education in the Sultanate of Oman, pg 25)

Eleventh Philosophy of Education: Education and Work

1 . The practical application of theoretical knowledge. 
2. Reinforce the values of work and production.

3. Appreciate all professions.

4. Develop basic job skills.

5. Align educational outcomes with the requirements of the comprehensive development of society and the needs of the labour market.

6. Develop work skills for local and international competitiveness.

7. Encourage a culture of professionalism and reinforce its effectiveness in the professional lives of individuals in the labour market.

Considering the needs of the nation, this study adopts Kolb's experiential learning cycle which utilizes the learners' experience on the topic, contextualizes it to the job market, and allows them to reflect on the experiences, concretise the concepts and implement the knowledge gained to societal needs. By active involvement in the four modes of the learning cycle, students develop an awareness of their responsibilities, capabilities and take ownership of the learning process. In other words, they cultivate autonomous behaviour in and out of class and in the work environment.

\section{LITERATURE REVIEW}

Successful experiential learners develop into autonomous learners with skills that enable them to undertake the responsibility to work alone or in a group (Moon, 2004). It is seen that no matter what activity is planned, reflection and application play a vital role in ensuring a deeper understanding of abstract concepts. (Clark, Threeton, \& Ewing, 2010) state that in order to acquire more in-depth understanding, learning should not halt at the experience stage; if this occurs, then the learner is denied the chance to absorb or retain valuable knowledge gained through experience.

\section{A. Kolb's Experiential Learning Model}

There is a large volume of published studies describing the role of experiential learning however, the current study adopts Kolb's experiential learning cycle, which has gained recognition in recent decades. Kolb draws his ideas of experiential learning from theories laid by Dewey, Lewin, and Piaget. A working definition of the learning process coined by Kolb is 'Learning is the process whereby knowledge is created through the transformation of experiences.' Kolb's experiential learning theory is a holistic theory that encompasses the learning process as an adaptation of the whole being, with sound background from humanistic concepts of learning. He characterized learning as (i) a process; (ii) a continuous process based on experience; (iii) a dialectic process; (iv) a holistic process of human adaptation; (v) a transaction between the individual and the environment; (vi) a process of creating knowledge. (pg 26-37)

According to Kolb, learning is cyclical in nature. The four-component cyclical mode of learning is known as the 'Kolb Learning Cycle.' For successful learning, the learner should involve actively in all the four modes, i.e., Concrete experience (CE), reflective observation (RO), abstract conceptualization (AC) and active experimentation (AE). The first stage requires the learner to be prepared to receive new experiences and fully immerse themselves in gaining knowledge from experience. The second stage is reflective observation, which is indispensable to any successful learning. As the stage suggests, the learner must reflect on the experience and observe any meaningful knowledge from various perspectives. This is followed by the abstract conceptualization stage where the knowledge gained from the two stages are integrated. In other words, their observations are integrated with rich learning experiences that would assist in creating and comprehending concepts. The last stage in the experiential cycle is the active experimentation, in which the learner transforms the new knowledge gained from observing and reflecting on the experience to that could be applied in making decisions and problem-solving.

\section{B. Experiential Learning Task Design}

Kolb's experiential learning cycle integrates knowledge from experiences by applying it to the formal learning setting and reflecting on the knowledge gained. The activities designed by the researcher are developed in a way to facilitate a smooth transition from one stage of the learning cycle to another. (Driscoll \& Driscoll, 2011) enumerate eight principles of good practice for all experiential learning activities laid down by the (National Society for Experiential Education, 2013) as; Intention, preparedness and planning, authenticity, reflection, orientation and training, monitoring and continuous improvement, assessment and evaluation and acknowledgment. The activity ensures that the experience is cyclic and completes the loop of the learning process. According to NSEE, the facilitator plays a major role in ensuring that the principles of experiential education are fulfilled. While implementing the experiential learning model, the facilitator chooses experiences that match with the learning outcomes, ensures that suitable resources are provided to facilitate the process of learning, and support learners in problem-solving and active experimentation (pg 26 , 27). (Burrell, Finch, Fisher, Rahim, \& Dawson, 2011) support the view that opportunities which involve students in the learning process prepare them to meet the needs of the future (pg 52). Consequently, the tasks prepared for this study include reflective learning logs, simulations, discussions, authentic case studies, pair work, and group work. All the tasks are intended to assist the progress of the learning cycle.

\section{Defining Learner Autonomy}


"Autonomy" is a complex terminology to be defined yet very significant in pedagogy. The term autonomy was first defined by Holec (1981) as "the ability to take charge of one's learning" cited in (Benson, pg 22). However, Benson claims that literature published on autonomy has rocketed drastically the past decades that it has complicated the definition of what "autonomy" really means. (P. Benson, 1997) and (Little) believe that autonomy is the capacity of the learner to take responsibility for their learning. There is a very thin line of difference between "capacity" and "ability". While Holec mentions "ability" of the learner, (Little) elaborates on "capacity" of the learner to take independent action, the willingness to plan, monitor, evaluate and set agendas for their own learning process. In order to carry out the tasks successfully, the learner needs to deploy appropriate strategies, more specifically cognitive strategies. (Oxford, 1999) summarized the definition of autonomy as:

Ability, attitude, + action $=$ autonomy $\rightarrow$ achievement

The learner's ability and willingness to execute a task independently, reflect on situational needs and ability to select appropriate strategies to accomplish a task successfully (pg 111).

In (Dickinson, 1995)'s view, the attitude of the learner plays an important role, where the learner should take ownership of the decisions they make about their own learning (pg 167). (Nunan, 1980)goes a step further away from ability and capacity to the degree of being autonomous. He endeavors to lead the learner away from the dependence on the teacher to autonomous learning. Nunan identifies nine steps to making the learner autonomous in the educational process (pg 195-203).

Step 1: Make instruction goals clear to learners

Step 2: Allow learners to create their own goals

Step 3: Encourage learners to use their second language outside the classroom

Step 4: Raise awareness of learning processes

Step 5: Help learners identify their own preferred styles and strategies

Step 6: Encourage learner choice

Step 7: Allow learners to generate their own tasks

Step 8: Encourage learners to become teachers

Step 9: Encourage learners to become researchers

As it is obvious from the steps stated above, if the learner creates their own goals, they are more likely to follow them since they are self-created, by thinking in the shoes of teachers and researchers, they are aware of their own preferred learning strategy and attempt at generating their own means of achieving the learning goals set by themselves. Sharing similar views,(Dickinson, 1995) points out that learner involvement in decision making ensures that learning is effective(pg 176). Pedagogically, most of the researchers on learner autonomy support the view that when learners are psychologically attached to the learning process, it is more meaningful and relevant. Autonomy is defined as an 'ability to use a set of tactics" to take control of one's learning (Sara Cotterall, pg 195). The tactics as described by Cotteral would include most of the steps specified by Nunan, such as goal setting, selection of materials, planning, monitoring and evaluating their own progress in learning. All aspects of learner autonomy are evident in kolbs experiential learning cycle, where the learners are made aware of their learning strategies, reflect on their experiences, set learning goals and take responsibility of learning in an out of class.

\section{Related Studies on Learner Autonomy}

"Before interventions aimed at fostering autonomy are implemented, it is necessary to gauge learners' readiness for the changes in beliefs and behavior which autonomy implies" (S. Cotterall 195). Are learners ready to accept responsibility? Are teachers confident in allowing learners to be autonomous? There are several such questions that challenge the practicality of theoretical assumptions on teacher-learner autonomy. Horwitz (cited in S.Cotteral) argues that "erroneous beliefs" of learners about language learning impedes their progress. Hence, before their negative beliefs transform them into low proficient learners, it should be controlled. (pg 196) An exploration of learners' perceptions and beliefs would enable a teacher to prepare their learners towards being autonomous. Several studies have been conducted to identify the learners' abilities, the willingness to take responsibilities and their attitudes towards learning activities.

(Van, 2011) conducted his study across 24 universities in Vietnam to investigate the perceptions of Non-English Majored students on being autonomous learners. It was a large-scale study that involved 631 students. The findings revealed that students were not aware of the concept of autonomy, and were satisfied with their current learning environment (pg 43, 46). (Hussein, 2014) wanted to examine learners readiness to be autonomous. He conducted his investigation on 140 students who were enrolled in two introductory courses in English at a university in Palestine. The study specially measured learners' readiness on aspects such as responsibilities, abilities and their readiness to perform autonomous activities in English. The data from questionnaires and interviews revealed that the teacher was held responsible for a student's success or failure. However, they were willing to exhibit autonomous behavior if they were given a chance to do so. The researcher calls for training to raise awareness of the benefits of autonomous learning (pg 323, 332-335). A similar study was carried out by (Üstünlüoğlu, 2009) in a university in Hong Kong involving 320 students and 24 teachers. The purpose of the study was similar to that of (Hussein, 2014). Additionally, the study investigated the influence of variables such as motivation level and gender on perceptions towards autonomy were also examined. It was evident from the quantitative data and interviews that both the students and the teachers were not in 
favor of autonomous learning. Students did not own responsibility for their learning, and the teachers do not view students capable of handling the responsibility for their learning. (Üstünlüoğlu, 2009) suggests a training programme be included in the curriculum (pg 154,160-162). While all the three studies (Van, 2011) (Üstünlüoğlu, 2009) (Hussein, 2014) reflect a lack of awareness and ownership of responsibilities by students and teachers, a study administered in a Polytechnic University in Hong Kong by (Chan, 2010) revealed positive views of learners regarding autonomy unlike the previous studies. The study used a survey to assess the attitude and expectation of learning a language, learning preferences, and the perceptions of teachers and students towards autonomous learning. The results were unexpected by the researcher. Students seemed to be aware of their role in the learning process, preferred learning styles and clear learning goals. Moreover, they were willing to take responsibility for the learning process, which is the main characteristic of being autonomous (pg 508, 514-515).

Another study was conducted in China by $(\mathrm{Xu}, 2009)$ to examine the extent of autonomous learning among Chinese postgraduate students. The results were not satisfactory. The surveyed students displayed no motivation or clear objectives towards autonomous learning despite being at the post graduate level. The researcher expresses concern that the students did not value the significance of English in their studies and did not participate cooperatively in English activities (pg 26-29). A study carried out in an Iranian context by (Farahani, 2014) involves 450 EFL learners, 219 female and 186 male. By analyzing data obtained through a questionnaire, semi-structured interviews and nonparticipant observations it was concluded that there was a gap between learner's awareness of autonomous learning and practical usage in the classroom. Learners felt that they were motivated, however, they believed that the teacher is indispensable and should be the one who should be responsible for creating awareness in the learners towards being autonomous (pg 100,109-110). To sum up, the studies dealing with students views on autonomy, it is apparent that students are partially aware of autonomy in language learning and perceive themselves motivated but consider the teacher as the dominant figure who is responsible for their progress in language learning. Although there are myriad studies on teacher's beliefs and perceptions of autonomy, a few studies of relevance will be discussed below.

A large-scale project on exploring teachers beliefs on learner autonomy was conducted by (Borg \& Al-Busaidi, 2012) at Sultan Qaboos University in Oman. 30.5\% responses were recorded through an online questionnaire, and 20 wellqualified staff were interviewed. A variety of perspectives were expressed. Despite providing opportunities to facilitate leaner autonomy, the teachers were not sure to what extent their learners utilized the chance given to them. Most of them believed that they have contributed to the promotion of learning autonomy by advocating a variety of pedagogical strategies. Additionally, they welcomed the idea of involving the learner in certain aspects of planning and organizing learning activities. The teachers felt restricted by the centrally defined curriculum which constrained them from experimenting with learner autonomy (pg 9, 20-21). Another interesting study was done in Turkey by (Balçıkanl1, 2010). The sample population comprised of 112 student teachers. The purpose was to identify the beliefs of student teachers about learner autonomy. A selected no of 20 teachers were interviewed apart from administering a questionnaire to 112 respondents. The study reported that the teachers were positive towards the concept of learner autonomy but were not comfortable with involving students in the decision making process (pg 92, 98). (Al Asmari, 2013) conducted his survey in the Kingdom of Saudi Arabia at Taif University. The aim of the study was to gather teachers' opinions on the practices of learner autonomy in their classes. The sample population consisted of 60 teachers of different nationalities. The data revealed that teachers were positive to the notion of students involving in decision making as compared to the student teachers view in (Balçıkanl1, 2010) study. Although the teachers seemed positive towards supporting autonomous learning, the researcher mentions that they lacked the training to promote autonomy (pg 4, 7).

Reflecting and reviewing the studies on teachers and learners beliefs and perceptions on autonomy provide an overall opinion that learners perceive themselves as autonomous but consider the teacher responsible. Teachers perceive themselves as facilitators of autonomy but are hesitant to handover certain aspects of the learning process to the learners. Each one of them has constraints on implementing or adopting autonomy to its fullest potential.

\section{RESEARCH METHODOLOGY}

\section{A. Participants}

The participants for this study were 60 full-time undergraduate students registered for Level 2, Semester One Business programme. It is to be noted that only full-time mode students were part of this study to avoid the influence of external factors that could be a threat to the validity of the study. The samples for this study were chosen using a convenience sampling technique based on convenience and accessibility. The majority population of this study were from a linguistically homogenous background (Arabic), aged between 20-23 years, and share common characteristics with regards to socio-cultural aspects. Hence convenience sampling was deemed as suitable. The intervention of the project was carried out in an English module class. The 'Professional Skills Module' was the last English module on the programme. The pre-requisite of the 'Professional Skills module' was the completion of two English modules in Level 1 .

\section{B. Data Collection Instrument}

(Chan, Spratt, \& Humphreys, 2002) designed a questionnaire to examine the relationship between the attitude of students and their perceptions on autonomous practice. The questionnaire adopted inputs from Deci (1995), Deci and 
Ryan (1985), Holec (1981) and Littlewood (1999). The questionnaire was influenced by Holec's notion of ability and responsibility to develop autonomy. It consisted of four main sections containing a total of 52 questions. The four sections focused on the learner's perception of their English teacher's responsibilities and their own responsibility, their ability at decision-making, reflect on their motivation to learn English and ponder over the different autonomous activities they involve in outside and inside the class. (Üstünlüoğlu, 2009) revised the questionnaire and piloted it to check for validity. The Cronbach Alpha coefficient was .81, suggesting that there was the consistency of responses. The instrument used for this study was the one adopted by (Üstünlüoğlu, 2009) as it was revised keeping in mind the Arabic context. Unlike the four sections in the questionnaire that was devised by (Chan et al., 2002) the background questionnaire asks the respondent to provide personal information regarding gender and motivation level. Section one is the section on responsibility, where students read the descriptors and select between three option; teacher's responsibility' student's responsibility' and 'both.' The next section (Items 11-20) draws their attention to their abilities, providing a 5-point Likert scale to choose their ability ranging from very poor to very good. The last section (21-41) is based on the activities they do inside and outside the class, with choice of preference ranging from never, rarely, sometimes, often and always.

\section{A sample of an Experiential Task}

Topic: SWOT Analysis (Strengths, Weakness, Opportunities, Threats)

Learning Outcome- To identify personal strengths and weakness and reflect on ways to overcome the weakness.

Task Description

Concrete Experience

Module name was written on the board as a starting point for a mind-map. Students' brainstormed ideas in groups on what they expected to learn in this module. Group representatives came forward to write the goals of the English module. Teacher initiates discussions and deliberates on setting goals to achieve the expected learning outcomes.

Reflective observation

Based on the goals they set for themselves, students completed a personal SWOT. They reflected on their strengths and weaknesses and identified possible threats and decided on an action plan to achieve the goals that they devised in the first part of the lesson. The teacher handed out the reflecting learning log sheet 1 for students to record their reflections.

\section{Abstract Conceptualization}

The knowledge from CE about the module expectations and RO - actively reflecting on the experience, they draw inferences on the possibilities of dealing with learning difficulties. At this point of time, the teacher gave each group an A3 size plain paper and asked students to work in groups and do a SWOT analysis for their educational institution (the University where they are currently studying in). Once it was completed, the A3 posters were displayed on the wall at a regular distance.

\section{Active Experimentation}

Students went around the class in sequential order, noting down any areas of the SWOT that they would approve or disapprove. After the given activity time, students returned to their seats, and the teacher elicited suggestions and recommendations that would benefit the institution. This activity generated a lot of language practice as students were eager to debate on strengths/weaknesses of the college that they were pleased/not pleased with.

Teachers Reflection on activity 1:

Rogers (1969) comments that "Experiential philosophy proposes that learners set their own goals and assess themselves" cited in (Knutson, pg 61). Students have completed two semesters of Level 1 and were used to being dictated about what to do and what not do. This was the first time; they felt the choice of setting goals was given to them. Owing to the nature of the module, there was room for being flexible with the goals of the module, although it is not officially permitted to do so. Although students set the goals, the teacher judiciously added a few objectives through negotiation students. So it was a twofold task. The activity not only created an awareness of their strengths and weaknesses, but it also gave them self-satisfaction as they set their own learning goal. "The curriculum does not start out by specifying and sequencing the material that is to be 'covered,' but it starts out with the activities, needs and emergent purposes of the learner" (van Lier, pg 53). The task activated their prior knowledge and acquainted them with strategies that would help them to overcome their learning difficulties. Reflection was conducted as a group within the task, however, the student's preferred to complete the individual self-reflection learning log at the end of the session.

\section{Description of the Procedure}

The study used 11 self-designed experiential learning activities and a learner autonomy questionnaire to gain insights into the change in perceptions of students on autonomy after the execution of the tasks for about 14 teaching weeks. Intervention is divided into three phases; the pre-intervention phase, during the intervention phase and the postintervention phase.

Pre-Intervention Phase

"When learners are not given a purpose for learning or not allowed to find a purpose on their own, the quality of learning is doubtful" (Buriak, McNurlen, \& Harper, 1996). In order to plan and organize experiential learning activities that would facilitate autonomy, it was imperative to explore student's perspectives on how autonomous they are. Data 
were collated through a learner autonomy questionnaire designed by Chan, Spratt, and Humphreys (2002) that was modified by (Üstünlüoğlu, 2009). The questionnaire was administered to students at the beginning of the first week of teaching as a pre-survey learner autonomy tool. Students' college identification numbers were used to direct the survey link to students' emails with the consent of the college management. Since the researcher was teaching both the experimental groups, it was convenient to take the students to a lab to complete the questionnaire.

During-Intervention Phase

The intervention phase comprised of instructional tasks designed to facilitate the experiential learning cycle and enhance language strategies. 11 tasks were planned for 11 teaching weeks, with each lesson lasting for 120 minutes (2 hours). A reflective journal activity was included during the 'reflective observation' stage of the experiential learning cycle, however, this depended on the task and time.

Post-Intervention Phase

The learner autonomy questionnaire was once again sent to students via email towards the end of the treatment schedule.

\section{RESULTS AND DISCUSSIONS}

\section{A. Responsibility}

TABLE-1

STUDENTS PERCEPTION OF RESPONSIBILITY

\begin{tabular}{|l|l|l|l|l|}
\hline Item no. & Post and Post & Teacher & Student & Both \\
\hline \multirow{3}{*}{2} & Students-Pre & $13 \%$ & $30 \%$ & $57 \%$ \\
\cline { 2 - 5 } & Post & $16 \%$ & $24 \%$ & $61 \%$ \\
\hline \multirow{3}{*}{3} & Students-Pre & $10 \%$ & $80 \%$ & $10 \%$ \\
\cline { 2 - 5 } & Post & $6 \%$ & $78 \%$ & $18 \%$ \\
\hline \multirow{3}{*}{4} & Students-Pre & $18 \%$ & $25 \%$ & $\mathbf{5 7 \%}$ \\
\cline { 2 - 5 } & Post & $16 \%$ & $\mathbf{5 9 \%}$ & $27 \%$ \\
\hline \multirow{3}{*}{5} & Students-Pre & $21 \%$ & $38 \%$ & $\mathbf{4 0 \%}$ \\
\cline { 2 - 5 } & Post & $29 \%$ & $\mathbf{4 1 \%}$ & $33 \%$ \\
\hline \multirow{3}{*}{6} & Students-Pre & $3 \%$ & $\mathbf{7 0 \%}$ & $26 \%$ \\
\cline { 2 - 5 } & Post & $35 \%$ & $18 \%$ & $\mathbf{4 9 \%}$ \\
\hline \multirow{3}{*}{7} & Students-Pre & $44 \%$ & $26 \%$ & $29 \%$ \\
\cline { 2 - 5 } & Post & $53 \%$ & $24 \%$ & $35 \%$ \\
\hline \multirow{2}{*}{8} & Students-Pre & $56 \%$ & $11 \%$ & $33 \%$ \\
\cline { 2 - 5 } & Post & $61 \%$ & $10 \%$ & $31 \%$ \\
\cline { 2 - 5 } & Students-Pre & $59 \%$ & $20 \%$ & $21 \%$ \\
\cline { 2 - 5 } & Post & $55 \%$ & $29 \%$ & $18 \%$ \\
\cline { 2 - 5 } & Students-Pre & $36 \%$ & $20 \%$ & $\mathbf{4 4 \%}$ \\
\hline \multirow{2}{*}{10} & Sost & $\mathbf{5 3 \%}$ & $24 \%$ & $24 \%$ \\
\cline { 2 - 5 } & Students-Pre & $\mathbf{4 4 \%}$ & $16 \%$ & $39 \%$ \\
\hline \multirow{2}{*}{} & Post & $24 \%$ & $\mathbf{5 5 \%}$ \\
\hline
\end{tabular}

Note: Reference Items in Table 1

\begin{tabular}{|l|l|l|l|}
\hline 1 & to ensure that you make progress during English lessons & 6 & to decide what students should learn next in your English lessons \\
\hline 2 & to ensure that you make progress outside class & 7 & to choose what activities to use to learn English in your English lessons \\
\hline 3 & to stimulate interest in learning English & 8 & to decide how long to spend on each activity \\
\hline 4 & to identify your weaknesses in English & 9 & to choose what materials to use in your English lessons \\
\hline 5 & to decide the objectives of your English course & 10 & to evaluate your learning \\
\hline
\end{tabular}

Table 1 presents the perceptions of students' pre and post the intervention phase. No change in perception was observed in Items 1, 2, 6, 7, 8. In both pre and post survey, students perceived a shared responsibility between teacher and student to ensure progress is made in the class, and in item no.2, they took complete responsibility $(80 \%, 78 \%)$ of monitoring their progress outside of the classroom This clearly indicates that they are aware of their responsibilities. They prefer to give the authority of planning lessons to the teacher. For example, they believe that the teacher should be the one to decide on activities (item 7) and duration of each activity (item 8). Their observation was valid, as during the implementation of the experiential activities, the teacher timed the stages of the lesson to facilitate the transition from the four modes of the learning cycle, so this was evident in their choice in the questionnaire.

The items numbers where a difference in perception was observed are 3,4,5,9 and 10, the percentages are highlighted in bold and shaded to draw attention to the variations. In the pre-autonomy survey, students believed that creating an interest in learning the language was the responsibility of both the teacher and the students, while in the post-survey, students considered it as their responsibility. The most prominent one was on' whose responsibility is it to identify the student's weakness in English.' In the pre-survey, students said it was the responsibility of both, student and teacher, but post-survey, they realised that it is their responsibility to detect their own weaknesses. This change of self-realization could be attributed to the reflective learning logs and personal SWOT analysis activity that was used during the cyclic learning process. What was surprising is, before the start of the intervention, students' perceived themselves as responsible for deciding on the objectives of the lesson. 
Contrary to the pre data, the post survey indicates a shared responsibility on the deciding the objectives of a lesson. These results are consistent with the study carried out by (Sakai et al.), where students wanted to participate in decision making. However, the notable aspect in the current study is that after the intervention of the experiential learning activities, students understood the meaning of objectives by creating tangible objectives along with the teacher during Activity 1- experiential task. As a result, they attributed the responsibility to both the teacher and the student in setting objectives, contrary to the perception of complete responsibility in the pre-autonomy survey. The results differ in the study conducted by (Üstünlüoğlu) who reported that students perceive teachers as responsible to decide the objective of an English course (pg158), however, this difference could possibly be due to the experiential activities given to the students in the current study. In Item 9, students felt it was a mutual responsibility of both to choose the teaching and learning materials, but in post-survey, they believed that choice of materials should be left to the teachers. In Item 10 , students earlier took no responsibility in evaluating their own learning, however, post the treatment, they thought it to be a collaborative responsibility to evaluate the learning process.

\section{B. Abilities}

If you have the opportunity, how good do you think you would be at?

\begin{tabular}{|l|l|l|l|}
\hline 11 & choosing learning activities in class & 16 & choosing learning materials outside of class \\
\hline 12 & choosing learning activities outside of class & 17 & deciding what you should learn next in your English lessons \\
\hline 13 & choosing learning objectives in class & 18 & deciding how long to spend on each activity \\
\hline 14 & choosing learning objectives outside class & 19 & identifying your weaknesses in English \\
\hline 15 & choosing learning materials in class & 20 & evaluating your learning \\
\hline
\end{tabular}

Items 11-20 in the questionnaire require the respondents to respond to their abilities to do certain activities. The choice is between poor, OK, good and very good. The pre-and post-survey have indicated similar areas of preference, so it is not illustrated. Students consider themselves "GOOD" in all activities listed. Starting with item number 11, students are good at choosing activities in class (pre 54\%/post 59\%), choosing learning activities outside class (41\%), choosing learning objectives in class $(56 \% / 49 \%)$, choosing learning objectives outside class (48\%/47\%), choosing learning materials in class $(43 \% / 53 \%)$, choosing learning materials outside class $(50 \% / 43 \%)$, deciding what you should learn next in your English lessons (48\%/41\%), deciding how long to spend on each activity (48\%/39\%), identifying your weaknesses in English (35\%/41\%), and evaluating your learning (43\%/57\%).

(Sara Cotterall, 1995) mentions that "autonomous learners not only monitor their language learning but also assess their efforts". According to Blanche (1988: p. 75), an appreciation of their abilities, the progress they are making and of what they can do with the skills they have acquired is essential if learners are to learn efficiently (pg 199).

\section{Frequency of Activities}

TABLE-II

STUDENTS PERCEPTION ON FREQUENCY OF ACTIVITIES (PRE-LEARNER AUTONOMY QUESTIONNAIRE)

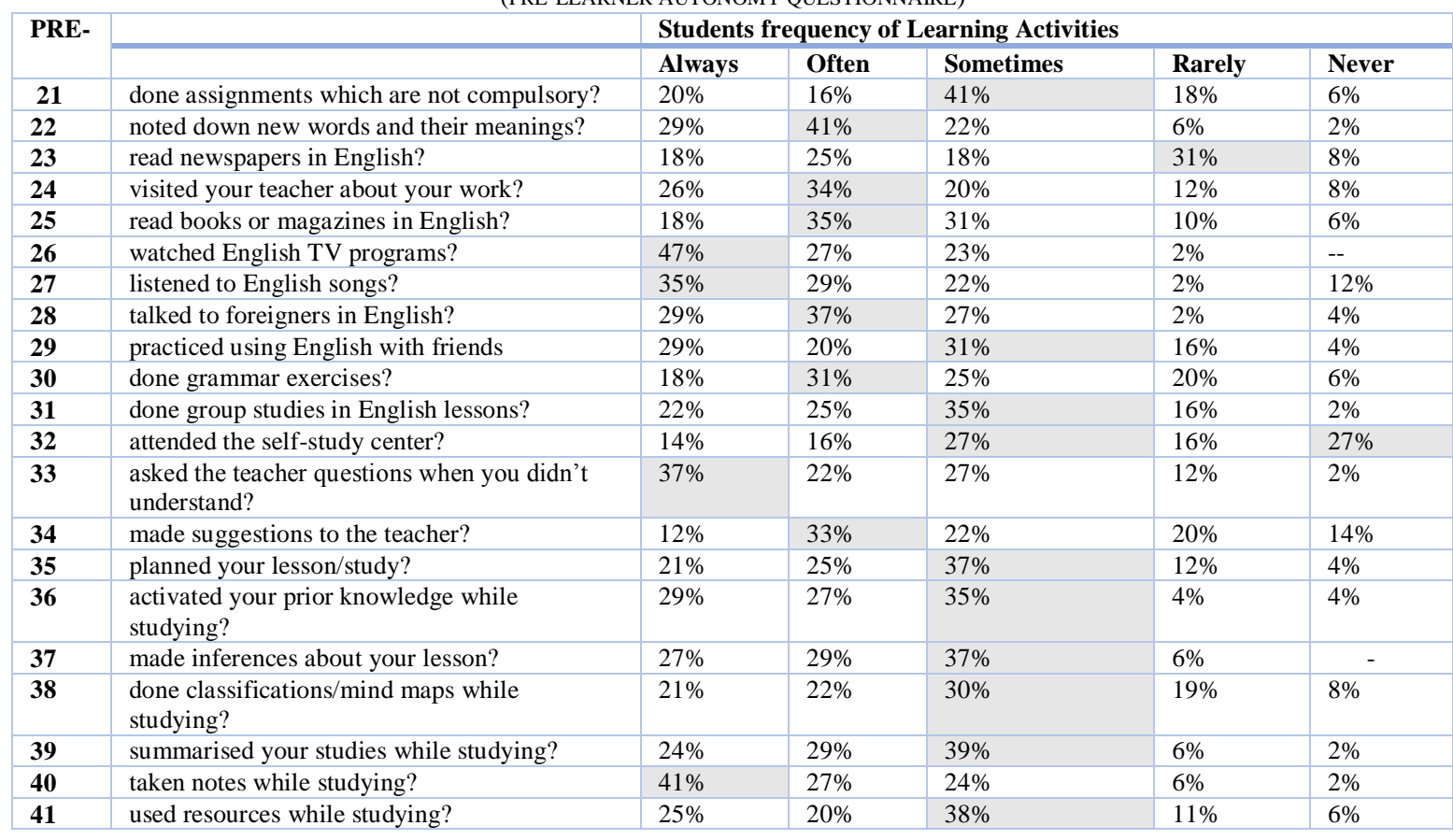


TABLE-III

STUDENTS PERCEPTION ON FREQUENCY OF ACTIVITIES (POST-LEARNER AUTONOMY QUESTIONNAIRE)

\begin{tabular}{|c|c|c|c|c|c|c|}
\hline & \multicolumn{6}{|l|}{ The post-students frequency of Learning Activities } \\
\hline & & Always & Often & Sometimes & Rarely & Never \\
\hline 21 & done assignments which are not compulsory? & $24 \%$ & $27 \%$ & $22 \%$ & $14 \%$ & $12 \%$ \\
\hline 22 & noted down new words and their meanings? & $24 \%$ & $51 \%$ & $18 \%$ & $4 \%$ & $2 \%$ \\
\hline 23 & read newspapers in English? & $12 \%$ & $16 \%$ & $41 \%$ & $16 \%$ & $14 \%$ \\
\hline 24 & visited your teacher about your work? & $24 \%$ & $22 \%$ & $40 \%$ & $8 \%$ & $6 \%$ \\
\hline 25 & read books or magazines in English? & $16 \%$ & $14 \%$ & $49 \%$ & $12 \%$ & $8 \%$ \\
\hline 26 & watched English TV programs? & $29 \%$ & $29 \%$ & $33 \%$ & $8 \%$ & $2 \%$ \\
\hline 27 & listened to English songs? & $39 \%$ & $8 \%$ & $27 \%$ & $20 \%$ & $6 \%$ \\
\hline 28 & talked to foreigners in English? & $29 \%$ & $35 \%$ & $24 \%$ & $4 \%$ & $8 \%$ \\
\hline 29 & practiced using English with friends & $22 \%$ & $35 \%$ & $31 \%$ & $10 \%$ & $2 \%$ \\
\hline 30 & done grammar exercises? & $8 \%$ & $29 \%$ & $39 \%$ & $16 \%$ & $8 \%$ \\
\hline 31 & done group studies in English lessons? & $15 \%$ & $40 \%$ & $33 \%$ & $12 \%$ & $2 \%$ \\
\hline 32 & attended the self-study center? & $16 \%$ & $20 \%$ & $65 \%$ & $35 \%$ & $12 \%$ \\
\hline 33 & asked the teacher questions when you didn't understand? & $45 \%$ & $22 \%$ & $29 \%$ & $2 \%$ & $2 \%$ \\
\hline 34 & made suggestions to the teacher? & $12 \%$ & $27 \%$ & $43 \%$ & $12 \%$ & $6 \%$ \\
\hline 35 & planned your lesson/study? & $22 \%$ & $27 \%$ & $40 \%$ & $7 \%$ & $4 \%$ \\
\hline 36 & activated your prior knowledge while studying? & $8 \%$ & $50 \%$ & $28 \%$ & $12 \%$ & $2 \%$ \\
\hline 37 & made inferences about your lesson? & $10 \%$ & $37 \%$ & $37 \%$ & $12 \%$ & $4 \%$ \\
\hline 38 & done classifications/mind maps while studying? & $10 \%$ & $29 \%$ & $39 \%$ & $10 \%$ & $12 \%$ \\
\hline 39 & summarised your studies while studying? & $29 \%$ & $37 \%$ & $22 \%$ & $8 \%$ & $4 \%$ \\
\hline 40 & taken notes while studying? & $43 \%$ & $33 \%$ & $16 \%$ & $2 \%$ & $6 \%$ \\
\hline 41 & used resources while studying? & $20 \%$ & $48 \%$ & $20 \%$ & $10 \%$ & $2 \%$ \\
\hline
\end{tabular}

Table 2 and 3 illustrate the pre and post survey results on students' perception of activities in and out of class. 41\% students sometimes do assignments that are not compulsory, but post-survey, the percentage is distributed in ' 20 s between always (24\%), often (27\%) and sometimes (22\%). It could be that students in the post-survey decide on the necessity of the assignment. In the experiential learning tasks, there were some sample assignments that students were asked to do in order to gain more experience in the activity although they were awarded marks. The percentage increased from $41 \%$ to $51 \%$ in the post-survey in students' habit of noting down new vocabulary words with their definitions. A big difference was observed in students reading English newspapers. In the pre-survey, $31 \%$ rarely read English newspapers, and in the post survey, $41 \%$ sometimes read English newspapers. This was an achievement as students rarely read Arabic newspapers so reading English newspapers was a far-fetched activity. This is confirmed by a study carried out by (Al-Bulushi \& Al-Issa, 2012) which concluded that $41 \%$ of students rarely read English newspapers. The increase in students reading newspapers is due to the fact that students engaged in real world activities in class that required them to update themselves regarding companies, job opportunities and other activities.

$34 \%$ of students visited the teacher often while the visits to the teacher reduced from 'often 'to 'sometimes' $(40 \%)$ in the post-survey. It could mean that students felt more independent than before or perceived themselves capable of dealing with academic issues. It was a similar case with the next item no.25. The frequency of reading books 'often' reduced from $35 \%$ to reading books or magazines sometimes (49\%). The intervention activities encouraged authentic materials like newspapers, case studies from internet and journals, this could be the reason for the reduction in reading books often. At the start of the new semester, $47 \%$ of students claimed that they always watched English programs on TV, however, in the post-survey the frequency of watching English TV programmes reduced to 33\%. At the time students took the pre-survey, they had just completed Level 1 and progressed to Level 2 . The results could mean that as students' progress to higher levels of the programme, they prioritize time spent on certain activities. Several English videos were played during the intervention period, so this could have reduced their need to watch English TV programmes.

Contrary to this, the majority of them acknowledged that they listen to English songs which were quite surprising since this was not a culturally accepted practice. Majority conceded talking to foreigners in English. The institution where the study is conducted accommodates students from different countries, so this provides opportunities for the locals to mingle and communicate with them. $31 \%$ of students 'sometimes' practice their English language skills with friends, while the frequency slightly rose from 'sometimes' to 'often' (35\%) in the post-survey. English is a foreign language in Oman, even a minor improvement in students' initiative to practice the target language is gratifying.

At Level 2 of the programme, there were fewer grammar exercises compared to the lower levels of the programme. Hence it was obvious that students at the pre-stage 'often' (31\%) did grammar exercises, but 'sometimes' (39\%) did such exercises in the post stage. A reasonable improvement in group activities has been observed between the pre and post survey. 35\% of students confirmed that they 'sometimes 'did group studies but post-treatment, $40 \%$ of students claim that they' often 'do group studies in English lessons. Most of the experiential tasks followed the four modes of Kolb's cyclic learning process which required students to work in groups at various stages. This could be the justification for the increase in percentage. A significant difference is observed in students using resources while studying. Earlier, only 38\% 'sometimes' referred to resources while studying, but post-intervention, students claimed that they used resource 'often' $(48 \%)$. The increase in the frequency of referring to resources is a positive change in 
study habits. Item no. 32 is closely linked to the previous statement on utilizing resources. While $27 \%$ only 'sometimes' attended the self- study center pre-intervention, the visit to the self-study center rose dramatically to $\mathbf{6 5 \%}$. This is an overwhelming change brought about in students' perception of independent learning. Student's perception of the teacher is that of a subject expert who clarifies their uncertainties in the learning process (37\% and 45\%) 'always' ask the teacher questions if they do not understand something. A rise in the percentage of students asking the teacher question is an achievement. (Sara Cotterall, 1995) explains that regular teacher feedback is given in the classroom, but effective learning depends on how learners utilize the given feedback. When learners are ready to share queries about the learning process with the teachers, it displays responsible behaviour, a characteristic of an autonomous learner. (pg 199)

Another notable difference was observed in item no. 36. Students 'sometimes' activated their prior knowledge while studying, but post-treatment, 50\% 'often 'activated their prior knowledge while studying. The first mode of the experiential cycle stimulates students' prior experiences before moving on to the reflection observation mode. Items 37 40 were about study skills that have been reiterated in all levels of the programme starting from Foundation level onwards, so there was not much of a difference observed. It was noted that students continue to make inferences, create mind maps while studying, take notes and summarise. The current study indicated an obvious change in student's perception in areas where they consider themselves accountable. (S. Cotterall, 2000) believes that the 'potential for learner autonomy increases as an individual's learning awareness grows.' Consequently, tasks or activities should be designed to stimulate reflection on the learning process (pg 112).

Students have realized that deciding objectives of the English course and the responsibility to evaluate their learning is a joint responsibility, however, with regards to the choice of materials in class, they realized the authority in this matter. It is no doubt that they feel the teacher is the ultimate decision-maker in choosing materials as they consider the teacher as the subject expert. Üstünlüoğlu confirms the claim that students sense that the teacher is the one who decides on the objectives of the course (pg 157). There was a substantial change in study habits identified in the post learner autonomy survey. Students developed independent study habits by attending the self-study study. There was an increase in the number of students who often (50\%) activated their prior knowledge while studying.

It can be inferred from the observations of the post autonomy questionnaire that students displayed balanced perceptions in segregating tasks between teachers and students thus displaying an interest in shared responsibility. The experiential learning tasks taught students to work independently and at the same time recognise the teachers' expertise. The classroom activities increased their knowledge of the current affairs of the country, drew their attention to job requirements for Omani graduates and identified organisations that provided financial support to start SME's (Small and Medium Businesses). The simulation and role play of group meetings, and interviews gave them the confidence to face interviews. It can be concluded that autonomy was achieved to some extent. As Sinclair et al., 2000, notes, 'complete autonomy, is an achievable, but idealistic goal', The development of an individual's potential is, in many ways, constrained by the cultural conventions and political aspirations of the society they belong to (cited in Chan, pg 506). Efforts to promote autonomy are an ongoing process and as quoted by Sinclair et al., it is achievable despite constraints.

\section{LiMITATIONS}

The major limitation of this study is the duration of the intervention. Although the study was spread across 14 teaching weeks, two sessions were missed due to college activities, and it had to be covered by borrowing class time from other lecturers. Another challenge that was felt was the time consumed for planning and preparing experiential learning tasks and materials. The researcher could not deviate from the approved course syllabus, so it was imperative to work with the existing materials and embed experiential learning tasks.

\section{IMPLICATIONS FOR FUTURE RESEARCH}

The findings of this study have some recommendations for future research. The study was limited in nature with a duration of 14 teaching weeks, however, the impact of ELM can be extended and followed up with the same cohort through a longitudinal study to observe autonomous behaviour in the next level. An experiential classroom environment provides a conducive climate for action research and exploratory studies. The Omani educational system is in search of an educational framework that produces competent graduates in the workforce, so alternative teaching methods and approaches can be tried and tested just as the current study employed ELM in teaching. There is a need for more studies to study the impact of ELM in the field of English language teaching. The current scenario illustrates several studies in medical, technical and engineering field of education, but very few in ELT, specifically in Oman.

\section{CONCLUSION}

This study indicated that ELM creates a safe, flexible and engaging classroom environment through social interaction, sharing of experiences and reflection. At the outset, students held the teacher responsible for learning within the classroom however after experiencing the intervention tasks there was a change in students' perception. They became more focused and accepted ownership of their learning. This shift from dependency to independency is vital to any 
work environment where the person has to take the initiative to solve problems rather than depending on the boss or the person in authority. The active involvement of students in the ELM activities depicts their enthusiasm and motivation towards being a part of the learning cycle. ELM prepares students for future careers by linking theory with practical implications thus instilling in them confidence in responding to the needs of the job market. The confronting challenge of educational institutions to generate employable graduates compels educators to revisit their teaching practices. (Silva) remarks that: "Rules, set by the government, make autonomous learning more and more impossible (pg 483). When the teacher is in the class, he/she is in charge of the teaching and learning process, all authority remains abstract and arbitrary, so why not take risks and experiment with innovative teaching methods that engage students and achieve set goals. Rather than dictating what the government or the universities should do or grieving on the defects of a particular system of education, it is suggested that the realization should start from the basic source, which is the teacher. There is no doubt that teachers are restrained by centrally approved syllabi, but within the given boundaries, the teacher has the flexibility to transform even a boring task into an engaging and active lesson.

\section{REFERENCES}

[1] Al-Bulushi, A., \& Al-Issa, A. S. M. (2012). Issues in Teaching and Learning English as a Foreign Language in the Arab World. Muscat: Sultan Qaboos University's Academic Publication Board. Retrieved from https://www.researchgate.net/publication/265922382 (accessed 17/08/2018).

[2] Al-bulushi, A. S. A. A. H. (2012). English language teaching reform in Sultanate of Oman: The case of theory and practice disparity. Educ Res Policy Prac, 11, 141-176.

[3] AL-Dhafiry, A. W. M. (2003). Unemployment in the gulf countries: reasons and remedies. Applied Econometrics and International Development, 3(3), 61-82.

[4] Al-Hussaini, A. (2001). University of the twenty first century: Opportunities and challenges for medical education. $S Q U$ Journal for Scientific Research, 1(1), 1-2.

[5] Al Asmari, A. R. (2013). Practices and prospects of learner autonomy: Teachers' perceptions. English Language Teaching, 6(3), $1-11$.

[6] Balçıkanlı, C. (2010). Learner Autonomy In Language Learning Student Teachers' Beliefs.pdf. Australian Journal of Teacher Education, 35(February), 90-103.

[7] Benson, P. (2007). Autonomy in language teaching and learning. Language Teaching, 40(01), 21.

[8] Borg, S., \& Al-Busaidi, S. (2012). Learner autonomy: English language teachers' beliefs and practices. British Council ELT. Retrieved from http://simon-borg.co.uk/ELTRP-Report (accessed 29/06/2016).

[9] Buriak, P., McNurlen, B., \& Harper, J. G. (1996). Toward A Scientific Basis For The Craft Of Teaching. Journal of Agricultural Education, 37(4), 23-27.

[10] Burrell, D. N., Finch, A., Fisher, J., Rahim, E., \& Dawson, M. (2011). The use of Engaging and Experiential Learning Innovative Teaching Practices for Graduate Students. Review of Higher Education \& Self-Learning. Retrieved from http://ezproxy.library.capella.edu (accessed 30/03/2015).

[11] Chan, V. (2010). Teaching in Higher Education Readiness for Learner Autonomy: What do our learners tell us ? Readiness for Learner Autonomy: what do our learners tell us ? Teaching in Higher Education, 6(December 2012), 37-41.

[12] Chan, V., Spratt, M., \& Humphreys, G. (2002). Autonomous language learning: Hong Kong tertiary students' attitudes and behaviours. Evaluation \& Research in Education, 16(1), 1-18.

[13] Clark, R. W., Threeton, M. D., \& Ewing, J. C. (2010). The Potential of Experiential Learning Models and Practices in Career and Technical Education \& Career and Technical Teacher Education. Journal of Career and Technical Education, 25(2), 4662. Retrieved from http://scholar.lib.vt.edu/ejournals.(accessed 12/7/2018).

[14] Cotterall, S. (1995). Readiness for autonomy: investigating learner beliefs. Elsevier Science Ltd, 23(2), 195-205.

[15] Cotterall, S. (2000). Promoting learner autonomy through the curriculum: principles for designing language courses. ELT Journal, 54(2), 109-117.

[16] Dickinson, L. (1995). Autonomy And Motivation A Literature Review. System, 23(2), 165-174. Retrieved from http://people.exeter.ac.uk (accessed on 17/07/2017).

[17] Driscoll, B. A. (2011). Graduates' perspectives regarding the impact of the integration of experiential learning in academic programs, Graduate Theses, and Dissertations. Paper 12116.

[18] Farahani, M. (2014). From Spoon Feeding to Self-Feeding: Are Iranian EFL Learners Ready to Take Charge of their Own Learning ? Electronic Journal of Foreign Language Teaching, 11(1), 98-115.

[19] Hussein, A. A. (2014). University EFL Learners' Perceptions of Their Autonomous Learning Responsibilities and Abilities. RELC, 45(3), 321-336. Retrieved from https://www.researchgate.net/publication/305567854.(accessed 18/07/2018).

[20] Knutson, S. (2003). Experiential learning in second-language classrooms. TESL Canada Journal, 20(2), 52-64

[21] Kolb, D. A. (1984). Experiential learning: experience as the source of learning and development (Vol. 82). Englewood Cliffs, NJ: Prentice Hall (accessed 07/05/2016).

[22] Little, D. (1999). Developing learner autonomy in the foreign language classroom: A social-interactive view of learning and three fundamental pedagogical principles. Revista Canaria de Estudios Ingleses, 38(38), 77-88.

[23] Moon, J. A. (2004). A handbook of reflective and experiential learning: Theory and practice. London: Routledge.

[24] National Society for Experiential Education. (2013). 8 Principles, 8-9. Retrieved from http://www.nsee.org/8-principles (accessed 30/08/2015).

[25] Nunan, D. (2003). Nine steps to learner autonomy. In Symposium (Vol. 2003, pp. 193-204).

[26] Oxford, R. L. (1999). Relationships between Second Language Learning Strategies and Language Proficiency in the Context of Learner Autonomy and Self- Regulation. Revista Canaria de Estudios Ingleses, (38), 109-126.

[27] P.Benson. (1997). Autonomy in language learning. System, 25(4), 584-588. 
[28] Philosophy of Education in the Sultanate of Oman. (2017). Retrieved from https://www.mohe.gov.om.(accessed 30/08/2018)

[29] Sakai, S., Takagi, a, \& Chu, M. (2010). Promoting Learner Autonomy: Student Perceptions of Responsibilities in a Language Classroom in East Asia. Educational Perspectives, 43(1), 12-27.

[30] Silva, W. M. (2008). A Model for the Enhancement of Autonomy. Delta, 24, 469-492.

[31] Üstünlüoğlu, E. (2009). Autonomy in Language Learning: Do Students Take Responsibility for Their Learning? Journal of Theory \& Practice in Education, 5 (2), 148-169.

[32] Van Lier, L. (2007). Action-based teaching, autonomy, and identity. Innovation in Language Learning and Teaching, 1(1), 4665.

[33] Van, N. T. (2011). Language learners' and teachers' perceptions relating to learner autonomy-Are they ready for autonomous language learning?. VNU Journal of Science: Foreign Studies, 27 (1), 41-52.

[34] Xu, J. (2009). A survey study of autonomous learning by Chinese non-English major post-graduates. English Language Teaching, 2(4), 45-69.

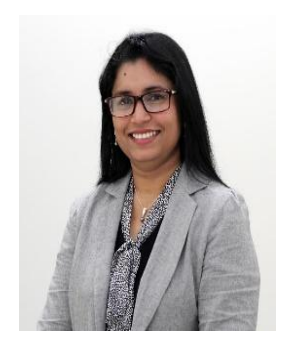

Anita Teresa Boggu is a doctoral candidate in English Language Teaching at Bharathiar University, Coimbatore, India. Besides her Master's Degree in the English Language, she holds a CELTA qualification. She currently works at Majan University College in Muscat, Oman as a Senior English Language Lecturer and a Programme Manager for the BA (Honors) in the English Language. Additionally, she has gained the status of a Senior Fellow of the Higher Education Academy (HEA), UK

Her major field of research is on experiential learning, language learning strategies and learner autonomy. She strives to underpin her teaching based on grounded research on teaching methodologies and endeavours to experiment with innovative and engaging classroom tasks to motivate learners.

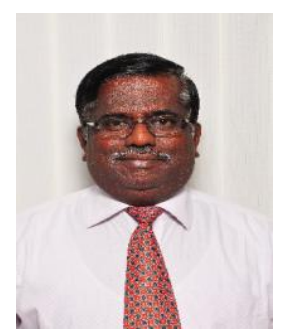

Sundarsingh is a Ph.D. in Linguistics, with more than two decades of experience teaching English to the Speakers of Other Languages both at Under Graduate and Post Graduate levels. His target groups include Arts, Science, Humanities, Engineering and Management students. He has been working in the area of Applied Linguistics with an emphasis on teaching English as a second language. His areas of interest include Cognitive Linguistics, CLIL, Stylistics, and English for Classroom Communication, Business English, Language Assessment and Language of Literature.

He has developed modules focusing on creating a conducive classroom for systematic and sustained innovation for language learning and communication. He has prepared language lab manuals for students of various levels and designed assessment modules. He has published about 40 articles in national and international journals of high repute. He has coordinated and conducted various faculty development programs, mainly dealing with classroom innovations, for the college and university teachers. He has served as a resource person for various faculty development and orientation programmes in colleges, universities, and schools in India.

$\mathrm{He}$ attended a training programme at Cambridge Assessment English, a part of University of Cambridge, UK. He has organized research and teaching practice workshop for Post Graduate students and Research Scholars 